\title{
Phytoprotection
}

\section{Index des auteurs, volume 78 Author Index, Volume 78}

Volume 78, numéro 3, 1997

URI : https://id.erudit.org/iderudit/706128ar

DOI : https://doi.org/10.7202/706128ar

Aller au sommaire du numéro

Éditeur(s)

Société de protection des plantes du Québec (SPPQ)l

ISSN

0031-9511 (imprimé)

1710-1603 (numérique)

Découvrir la revue

Citer ce document

(1997). Index des auteurs, volume 78. Phytoprotection, 78(3), 129-130.

https://doi.org/10.7202/706128ar d'utilisation que vous pouvez consulter en ligne.

https://apropos.erudit.org/fr/usagers/politique-dutilisation/ 


\section{A-B}

Adbullahi, A.E.

Ayer, W.A.

Beaulieu, C.

Bélair, G.

Bélanger, R.R.

Belzile, F.

Benlhabib, $\mathrm{O}$.

Bernier, L.

Boivin, G.

Brasier, C.M.

Brûlée-Babel, A.L.

Brzezinski, R.

Bussières, G.

C

Cambron, S.

Careau, D.

Carrière, $\mathrm{Y}$.

Cavers, P.B.

Charest, P.-M.

Chouinard, G.

Coderre, D.

Collin, J.

Comeau, A.

Cormier, D.

Côté, L.

Côté, N.

Couture, L.

\section{D-E}

Daayf, F.

Dal Bello, G.M.

Demianyk, C.J.

Déry, C.

Dodier, $M$.

Dostaler, D.

Dubuc, J.-P.

Dusabenyagasani, $M$.

Et-touil, A.

Eudes, F.

\section{F-G}

23

Faucher, E.

43

105

$43,87,90,95$

Fleurat-Lessard, F.

91,93

Fortier, J.-J.

Fortier, M.

Fourar, R.

89

105

Fournier, $\mathrm{F}$.

Fournier, Y.

85

35

86

89

85,89

Giguère, $M$.

Gingras, D.

Goyer, C.

95

85

$43,87,90$

86

\section{H-J}

Hamelin, R.C.

53

Hance, $T$.

Hanley, J.

89

11

61

Hesbois, B.

89

91,93

Hogue, R.

87,90

Hoy, M.A.

Jayas, D.S.

Jimenez, L.D.

90

75

99

86

117

53,88

17,88

67

90

87

17

\section{L-M}

Labbé, C.

87

Labrie, C.

Lacroix, M.

Laflamme, G.

Lagacé, $M$.

Lapalme, S.

Lapointe, G.

Leclerc, $P$.

87,90

89

86, 91

85

117

94

90

87

Lemieux, $C$.

91,93

125

Leroux, G.D.

92,93

Lori, G.A.

125

Lucas, É.

117

92

67

93

17

86 


\section{N-R}

Ngouajio, M.

Noel, C.

Ohm, H.W.

Ouellette, G.B.

Patterson, F.L.

Platt, H.W.

Pronovost, R.

Richard, S.

Rioux, S.

Rochefort, L.

Rochefort, S.

Roy, S.

Ruest, L.

\section{S-W}

91, 93 Saint-Pierre, C.-A. 92

89 Séguin, A. 94

61 Sharma, H.C. 61

93 Tardif, F.J. 92

61 Tewari, J.P. $\quad 99$

1 Toussaint, $\mathrm{V}$. 43

93 Vachon, J. 95

94 Valois, D. 43

88, 92 Vincent, C. 11

89 White, N.D.G.

86

90

43 